\title{
The role of bigram frequency in the perception of words and nonwords
}

\author{
GLENN A. RICE \\ Nichols College, Dudley, Massachusetts 01570 \\ and \\ DAVID OWEN ROBINSON \\ Brown University, Providence, Rhode Island 02912
}

\begin{abstract}
Adult subjects decided whether strings of four, five, or six letters formed words or nonwords. Words and nonwords were equally probable stimuli, and there were equal numbers of stimuli of high and low mean bigram frequency. Half the words were common and half occurred rarely in printed English. Mean bigram frequency had no effect on subjects' response times for common words and for nonwords, but the reaction times for rare words were significantly longer for words of high mean bigram frequency than for words of low mean bigram frequency. This result may be accounted for by a modification of Rumelhart and Siple's (1974) model of word perception to include the mapping of simple features to units which correspond to common spelling patterns.
\end{abstract}

The word apprehension effect is a well established phenomenon (Neisser, 1967; Smith \& Spoehr, 1974). A string of unrelated letters (a nonword) requires a longer exposure for accurate report than a word composed of an equal number of letters. Miller, Bruner, and Postman (1954) showed that this superior report accuracy was not limited solely to meaningful words. They used tachistoscopic presentations of nonword stimuli which varied in their approximation to the orthographic structure of English, and found that the accuracy of report was greater the more the stimulus approximated English.

A number of experiments have shown that there are components of the word apprehension effect which are not attributable to memory limitations. For example, Reicher (1969) followed a tachistoscopic presentation of a stimulus letter-string with two letters, one above and one below the position of a letter in the original stimulus. The subjects' task was to say which of the two letters had been presented in the stimulus letter-string. Accuracy was approximately $8 \%$ greater for letters presented within four-letter words than for letters presented within nonwords of the same length. A number of studies by Gibson (e.g., Gibson, Osser, \& Pick, 1963) have shown that more letters are correctly reported from a tachistoscopic exposure of a pronounceable nonword than from an unpronounceable nonword, and Baron and Thurston (1973) have shown that this advantage still holds when Reicher's forced choice task is used.

In addition to the difference between words and nonwords, there is a similar perceptual advantage for common English words over rare words of the same

This research was supported in part by Grant No. GB-34122 from the National Science Foundation to Dr. Richard B. Millwand. The authors gratefully acknowledge the comments of R. B. Millward, M. J. Adams, and K. T. Spoehr on earlier drafts of this paper. length. Howes and Solomon (1951) and Solomon and Howes (1951) showed that common words can be recognized at a shorter exposure than rare words. Similarly, when subjects are asked to say whether a string of letters forms a word or a nonword, their responses are faster to a common word than to an uncommon word (Rubenstein, Garfield, \& Millikan, 1970; Rubenstein, Lewis, \& Rubenstein, 1971). Smith and Spoehr (1974) have argued that reaction time and accuracy of report may be considered converging measures in word perception tasks.

Considering these studies together, one may suggest that the word frequency effect and the word apprehension effect may be mediated by the same cues. That is, there is some attribute which certain nonwords have in common with words that gives them a perceptual advantage over other nonwords in the same manner that common words show an advantage over rare words. In general, this attribute may be labeled orthographic regularity. A letter-string of high orthographic regularity, such as BUNE, is made up of sequences of letters which occur commonly in English, whereas a letter-string of low orthographic regularity, such as NBUE, is made up of improbable sequences. A measure of the orthographic structure of any letter-string may be calculated by determining the frequency with which adjacent pairs of letters (bigrams) occur in printed English text. Thus the mean bigram frequency of BUNE is higher than that of NBUE.

Bigram frequency may be used as a stimulus measure in word perception experiments designed to determine the extent to which subjects make use of their knowledge of orthography. Although the mean bigram frequency of a word correlates with its overall frequency of use in English, it is possible to manipulate these variables factorially. That is, there are common words that 
Table 1

Bigram Frequency: The Mean Bigram Frequency Over All Stimuli Within Each of Six Stimulus Groups

\begin{tabular}{cccc}
\hline \multirow{2}{*}{$\begin{array}{c}\text { Bigram } \\
\text { Frequency }\end{array}$} & Common & Rare & Nonword \\
\cline { 2 - 4 } High & 938 & 1063 & 1015 \\
& $\mathrm{~N}=15$ & $\mathrm{~N}=15$ & $\mathrm{~N}=30$ \\
Low & 205 & 199 & 209 \\
& $\mathrm{~N}=15$ & $\mathrm{~N}=15$ & $\mathrm{~N}=30$ \\
\hline
\end{tabular}

nevertheless have a low mean bigram frequency and, conversely, rare words with a high mean bigram frequency. Word frequency and bigram frequency have been varied in a number of studies in which letter-strings were presented tachistoscopically and the subject's task was to correctly identify the stimuli (Owsowitz, 1963; Biederman, 1966; Broadbent \& Gregory, 1968; Rumelhart \& Siple, 1974). All four studies reported a word-frequency effect (with accuracy for stimuli of high word frequency higher than for stimuli of low word frequency), but in two of the studies a paradoxical effect of bigram frequency was also noted. Both Owsowitz and Broadbent and Gregory reported that, for stimuli with low frequency of occurrence in English, stimuli of low mean bigram frequency are better reported than those of high mean bigram frequency, while Biederman and Rumelhart and Siple failed to find this apparent paradox.

The paradoxical effect of bigram frequency for rare words is a controversial one, since just as many studies have failed to find it as have found it. Moreover, the whole report task was used in both experiments where the effect was found and in the Rumelhart and Siple experiment. This paradigm is open to a number of criticisms (cf. Smith \& Spoehr, 1974) and in particular does not distinguish between perceptual effects and effects due to short-term memory limitations. The present experiment is an attempt to verify the existence of the bigram effect using a procedure designed to overcome this criticism. The memory confound was eliminated by using the reaction time task of Rubenstein et al. $(1970,1971)$ in which the stimulus is shown in a long exposure and the subject is required to say whether the stimulus is a word or nonword. If the orthographic regularity of a stimulus, as measured by bigram frequency, aids perception, then letter-strings having high bigram frequency should be responded to more rapidly than those of low bigram frequency. In addition, the subjects' responses to common words should be faster than those to rare words, as found by Rubenstein et al. In addition to avoiding the confounding with short-term memory, the present experiment controlled the correlation between word frequency and bigram frequency. By factorially varying these two variables, the degree to which each affects perception can be determined more accurately than in past studies.

\section{METHOD}

\section{Subjects}

The subjects were 24 volunteer undergraduate students enrolled in introductory psychology courses at Brown University. All subjects were native speakers of English.

\section{Stimuli}

The test stimuli (see Appendix) consisted of 60 words and 60 nonwords. Within each category there were 20 stimuli of each of three lengths: four, five, and six letters. Half of the words were common words and half were rare words. Each of the common words occurred more than 150 times in the Kucera and Francis (1967) corpus of approximately one million words of English prose, and the mean frequency of the common words was 398. The rare words occurred only once in the same word count. No plurals, proper nouns, abbreviations, or words containing hyphens or apostrophes were used. To insure that rare words with high bigram frequency were not merely under-sampled words in the Kucera and Francis corpus, the frequencies were reestimated using the Carroll, Davies, and Richman (1971) norms. No significant differences were found between words with high- and low-frequency bigrams. The nonwords were generated by a computer program which selected letters according to their frequency of occurrence in English as determined by Mayzner and Tresselt (1965). That is, the nonwords were first-order approximations to English words. Nonwords which contained embedded real words of length three or more letters were excluded. Finally, for each type of stimulus (common, rare, or nonword) and for each letter-string length, there were equal numbers of stimuli of high and low bigram frequency.

The actual stimuli used were chosen as follows. A list of possible stimuli which conformed to the criteria discussed above was drawn up for each of the three stimulus types. The mean bigram frequency for each possible stimulus was calculated by summing the frequency of each of its pairs of adjacent letters as indexed in Mayzner and Tresselt's (1965) corpus of 20,000 words of English prose. This sum was divided by the number of bigrams in the letter-string, which is one less than the number of letters. The three lists were then ordered according to the mean bigram frequencies and widely separated groups of words were selected from the beginning and end of each list to form the high and low bigram frequency stimuli.

This procedure does not control for the homogeneity of bigram frequency within each stimulus. The mean bigram frequencies were similar across the three stimulus ty pes as shown in Table 1. The frequencies used in this computation were the total frequencies, from Mayzner and Tresselt (1965), that is, the frequency summed over all positions and all word lengths. It could be argued that the rare words of high bigram frequency were made up of common bigrams which occurred in unusual positions (and hence had low pronounceability). When position is taken into account and the mean bigram frequency is computed for words of each length, the overall mean bigram frequency for rare words of high bigram frequency was slightly lower $(81.05)$ than the mean bigram frequency for common words of high bigram frequency (95.51). However, this difference is small compared with the mean bigram frequency for rare words of low bigram frequency $(24.40)$ and common words of low bigram frequency $(46.46)$

\section{Apparatus and procedure}

The experiment was controlled by a Digital Equipment Corporation PDP-8/L computer which presented the stimuli on small television monitors. The system has been described in detail elsewhere (Millward, Aiken, \& Wickens, 1972). Black upper case letters were displayed on a white background. Each 
Table 2

Errors: The Percentage of Incorrect Responses Made by All Subjects for Each Stimulus Type

\begin{tabular}{ccccc}
\hline & \multicolumn{4}{c}{ Word } \\
\cline { 2 - 5 } Bigram & & Frequency & \\
\cline { 2 - 5 } Frequency & Common & Rare & Nonword & Total \\
\hline High & 1.7 & 10.0 & 3.8 & 4.8 \\
Low & 2.2 & 3.1 & 1.7 & 2.2 \\
Total & 1.9 & 6.5 & 2.7 & 3.5 \\
\hline
\end{tabular}

character subtended an angle of $0.33 \mathrm{deg}$ at a viewing distance of 18 inches. The subjects made their responses on teletype keyboards by pressing keys which hid been designated "yes" (for a word) and "no" (for a nonword). Half the subjects used the right hand to respond "yes" and the left hand to respond "no", while the other half of the subjects used the opposite assignment. The subject's reaction times were measured by the computer to an accuracy of $1 \mathrm{msec}$.

The subjects were informed of the sequence of events in each trial and were told that their task was to determine whether the stimulus was a word or a nonword. Each trial began with the words "TYPE SPACE WHEN READY" being displayed on the screen. When the subjects were ready, they pressed the space bar and the stimulus was displayed after a delay of about 0.5 sec. The stimulus was shown in a position which corresponded to the leftmost characters of the ready message and it remained in view until the subjects made a response. The subjects received no feedback and the ready message returned to the screen after a brief delay. The subjects were informed that the experiment consisted of two groups of trials separated by a short rest period and that the first group was to be considered practice. The subjects were also told that they were to expect an equal number of word and nonword stimuli.

Subjects began by responding to 48 practice trials in which the stimuli were 24 words and 24 nonwords which conformed to the same criteria as the test stimuli. The practice stimuli were shown in a randomly determined order which was the same for all subjects. After a few minutes rest, the subjects responded to the 120 test stimuli which were presented in a different random order for each subject.

\section{RESULTS}

\section{Errors}

The overall error rate was low with a mean value of $3.47 \%$ for all subjects. The distribution of incorrect responses is shown in Table 2. As might be expected, subjects made most errors in responding to rare words and to nonwords, and this effect is most noticeable for stimuli of high bigram frequency $\left(\chi^{2}=14.94\right.$, $\mathrm{p}<0.001)$.

\section{Reaction time}

The mean reaction time of all subjects for each stimulus type is shown in Figure 1. The means presented are for correct responses only and exclude six reaction times longer than $3 \mathrm{sec}$, for which it is reasonable to assume that the subject was not paying attention at the time of stimulus presentation. Inspection of the data revealed no effect of string length and this variable was not considered in further analyses.

An analysis of variance was performed on the reaction time data in which bigram frequency and word frequency were treated as fixed effects (with two and three levels, respectively) and subjects and items within each stimulus group were treated as random effects following the considerations pointed out by Clark (1973). The analysis followed Winer's (1962) procedures for hierarchical designs and necessitated the use of quasi-Fs to test the main effects of bigram frequency and word frequency. To reduce the computational complexity the following simplifications were adopted. Firstly, the erroneous responses and the six reaction times over $3 \mathrm{sec}$ were treated as missing observations and were replaced by the mean reaction time of that subject to stimuli of the same word and bigram frequency. Secondly, in order to have equal numbers of observations for each of the three word types (common, rare, and nonword), the response to every other nonword was discarded. Using this procedure, the factor of word type was highly significant $\left[F^{\prime}(2 / 94)=13.36\right.$, $p<0.001]$. These data show the familiar word-frequency effect with the response times for rare words longer than those to common words. The factor of mean bigram frequency was also significant $\left[F^{\prime}(1 / 70)=8.40, p<0.01\right]$, as was the interaction of the two main effects $[F(2 / 46)=5.14, p<0.05]$. As is evident in Figure 1, there is a large difference in reaction time between the stimuli of high and low mean bigram frequency only for rare words. Post hoc $t$ tests indicated that this difference was significant $[\mathrm{t}(46)=5.12$, $\mathrm{p}<0.01]$, while the differences for common words and nonwords were not. The analysis showed a significant between-subject variation, $[F(23 / 1932)=57.38$, $p<0.001]$.

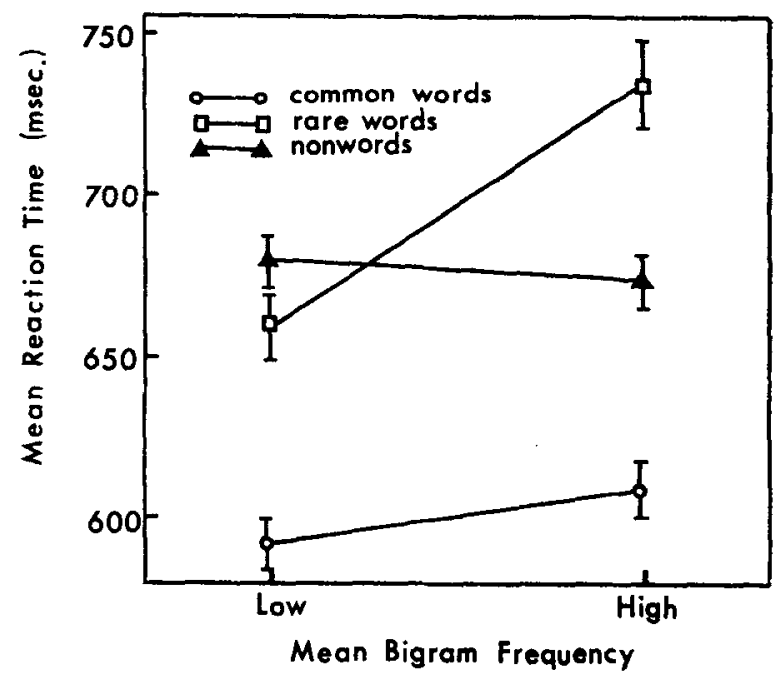

Figure 1. Mean reaction times for correct responses to common words, rare words, and nonwords as a function of the mean bigram frequency of the stimulus. Measure of variability shown is \pm 1 standand error. 


\section{DISCUSSION}

The results of the present experiment are consistent with those of Owsowitz (1963) and Broadbent and Gregory (1968). As in those studies, a paradoxical bigram frequency effect was found in which rare words containing low frequency bigrams were more perceptible than those containing high frequency bigrams. Rumelhart and Siple (1974) have suggested that the paradoxical effect is a function of the degree to which subjects expect only words as stimuli as compared to both words and nonwords. In the studies by Owsowitz and by Broadbent and Gregory only words were used as stimuli. On the other hand, in the experiments of Biederman (1966) and Rumelhart and Siple (1974) the stimuli also included nonwords, and no such paradoxical effect was found.

Rumelhart and Siple proposed that the subjects' expectations about the stimuli influenced their guessing behavior when the tachistoscopically presented stimuli were not uniquely identified. More specifically, according to their model, subjects extract features from the presented stimulus until either its iconic representation has faded or until it has been identified. In tachistoscopic presentations, the icon will often fade before identification has occurred. The subject, then, must choose his response from among those letter-strings which are compatible with the extracted features. His choice is also biased by his expectation about what stimuli will be presented. If only words are expected, the set of compatible letter-strings will be composed of only words, while if both words and nonwords are expected, it will be composed of all possible letter-strings. The paradoxical effect is caused by this postulate in conjunction with the fact that common and rare words do not have the same distribution of letters (Landauer \& Streeter, 1973). Bigrams may acquire high frequency by occurring in a few words which are very common or by occurring in many different words of moderate frequency. Although no specific evidence has been reported concerning the distribution of bigrams in rare and common words, it is reasonable to assume that at least some bigrams acquire high frequency through occurring in many different words. If high frequency bigrams tend to occur in a larger number of words than do low frequency bigrams, then at any given time prior to identification, stimuli containing high frequency bigrams would yield a larger number of compatible words than would stimuli containing low frequency bigrams. Thus, if the subjects expect only words, stimuli containing high frequency bigrams will produce either poorer guessing performance in a report task where stimulus exposure is not sufficient for complete processing, or will require a greater amount of processing time in a reaction time task. On the other hand, when both words and nonwords are expected and all possible letter-strings are then being considered, the effect does not obtain since high and low frequency bigrams will occur in an equal number of compatible strings.

The current data appear to weaken the Rumelhart and Siple position. Subjects clearly expected both words and nonwords, yet the paradoxical effect of bigram frequency was observed. However, it is conceivable that the use of the reaction time task induces a change in the subjects' processing strategies. In the reaction time task, the subject must make a decision about whether the stimulus is a word or not. The most efficient strategy for this may be for the subject to begin processing the stimulus as if he were trying to identify a word (as in the report procedure when only words are expected). Words which are incompatible with the extracted features at any given time would be eliminated from consideration. A "no" response is made only when there are no words left which are consistent with the extracted features. Since the compatible set of letter-strings is composed only of words, the subject's behavior will parallel that found with the report procedure when only word stimuli are expected. For nonword stimuli, which have few features compatible with real words, all members of the set of possible words are quickly eliminated, permitting a fast "no" response. For instance, if the stimulus were CKURGL, all members could be eliminated as soon as the initial CK has been detected. In this situation, the subject may, in fact, make a response before all the element letters of the stimulus have been identified. The "no" responses to nonwords are not always faster than "yes" responses to common words since on some trials all the element letters must be identified and since reaction times show a yes-no bias (Trabasso, Rollins, \& Shaughnessy, 1971).

Two problems still arise with Rumelhart and Siple's account of the paradoxical bigram effect. First, the paradoxical effect is not predicted for extremely low frequency words (frequency less than 10) according to their model, yet in the present study, in which rare words occurred only once in the Kucera and Francis corpus, the effect was found. Second, it is not clear why a parallel effect is not found for common words.

One basic modification of Rumelhart and Siple's formulation may alleviate these problems. Their model postulated two levels: a set of features extracted from the stimulus and a set of possible letter strings which are compatible with these features. Rumelhart and Siple's model may be extended by supposing that there exists some intervening stage in which the features extracted are mapped to units corresponding to common spelling patterns. This notion has been discussed in detail by Wheeler (1970) and Smith (1971). The discussion which follows assumes that these common spelling patterns may vary in size from as small as a bigram to as large as a syllable. The number and size of these pattern units are assumed to be a function of the familiarity of a word for a subject. This intervening stage of processing accounts for differences in perceptibility of various letter-strings 
in two possible ways. Firstly, when features have faded from an iconic representation these intervening units would be an extra repository of information. Secondly, these units may permit faster processing of features either because larger features may be used (Wheeler, 1970 ) or because a smaller number number of features is needed to identify a pattern unit than to identify the component letters of that unit.

With this modification it can be argued that there is no paradoxical effect of bigram frequency for common words because they are identified through spelling patterns larger than bigrams. Common words with low mean bigram frequency nonetheless contain relatively familiar orthographic patterns which are larger than two letters. An example will clarify this point. The bigram YO was counted 339 times in Mayzner and Tresselt's (1965) sample and therefore may be considered a relatively rare bigram (cf. Table 1), but the bigram is part of the word YOU which is a very common word and hence is a highly familiar orthographic pattern. That is, bigram frequency is not a completely adequate measure of orthographic regularity. Common words are more likely to contain larger orthographic units which facilitate perception. The processing of larger units will tend to dominate any effect due to smaller patterns. Thus any bigram effects on common words may be masked by the effects of larger spelling patterns.

Any model of word perception should be compatible with the basic principles of reading and the ideas presented here are intended to be compatible with what is known about the reading process. For instance, it is well known that subjects can make use of the redundancy of language to reduce the amount of processing required to recognize the words of a sentence. At times when the expected set of stimuli is very small (such as at the end of the sentence) the reader need only process a few features to confirm his expectations. At other times, when the expected set of stimuli is very large (such as in a word perception experiment) it may be necessary for the subject to make use of a large number of features and a large number of spelling pattern units of different sizes. A model of word perception which takes into account the subject's knowledge of the orthographic structure of the language and his expectations in a particular situation would be consistent with the flexibility of human information processing.

\section{APPENDIX}

\section{COMMON WORDS}

\section{High Bigram Frequency}

WANTED, AROUND, INDEED, CHANGE, GROWTH, WATER, HEARD, HEART, THIRD, THOSE, WHAT, KIND, FIND, WANT, AREA.
Low Bigram Frequency

OFFICE, SIMPLY, SOCIAL, POLICY, FAMILY, VOICE, MIGHT, SPACE, VALUE, TODAY, FACT, MUCH, BACK, DOWN, TURN.

\section{RARE WORDS}

High Bigram Frequency

ANTHEM, COHERE, DISHED, CIPHER, KINDER, MINER, RARER, PITHY, HERON, THINE, REND, HARE, WARE, CHAR, CANT.

\section{Low Bigram Frequency}

FUMBLE, MUMBLE, UNHURT, GIGGLE, DROWSY, SNOOP, EXALT, UNCAP, DAUNT, SLOOP, FLOP, CLOD, CHUM, LAVA, PLOD.

\section{NONWORDS}

\section{High Bigram Frequency}

THFEOR, HESUTS, EEAHET, DMTHNE, SELKHE, HEDLTN, ICRCHE, FHPHES, DMWTHV, HETNNL, EHEAK, FTHLT, TMHED, GTHHR, HESMC, THMYA, IWTHP, NIHEE, EOMHE, OTERO, WATH, ARND, ATHW, THNG, LRTH, PHEA, GHET, IHET, AJHE, HESL.

\section{Low Bigram Frequency}

AVCEEO, HLTNTE, RTTAYE, ILAOMH, RUUEDI, TIHHIM, SLWDES, ENLRLS, TRNASN, OTTOGH, CEEKT, PUIEE, OASYA, DYITT, COAEE, ELOIO, HHYST, LTQEN, ETDEC, AMLEW, NEOE, KKNE, IELT, GNNE, HYTE, WLEH, WHNS, NEOB, EEHT, SOOC.

\section{REFERENCES}

Baron, J., \& Thurston, I. An analy sis of the word-superiority effect. Cognitive Psy chology, 1973, 4, 207-228.

Biederman, G. B. The recognition of tachistoscopically presented five-letter words as a function of digram trequency. Journal of Vexbal Leaming and Verbal Behavior, 1966, 5, 208-209.

Broadbent, D. E., \& Gregory, M. Visual perception of words differing in letter digram frequency. Journal of Verbal Learning and Verbal Behavior, 1968, 7, 569-571.

Carroll, N. B., Davies, P., \& Richman, B. The American heritage word frequency book. Boston: Houghton Mifflin, 1971.

Clark, H, H. The language-as-fixedeffect fallacy: A critique of language statistics in psy chological research. Journal of Verbal Learning and Verbal Behavior, 1973, 12, 335-359.

Gibson, E. J., Osser, H., \& Pick, A. D. A study of the development of grapheme-phoneme correspondences. Journal of Verbal Learning and Verbal Behavior, 1963, 2, 142-146.

Howes, D. H., \& Solomon, R. L. Visual threshold as a function of word-probability. Joumal of Experimental Psychology, $1951,41,401-410$.

Kucera, H., \& Francis, W. N. Computational analysis of present-day American English. Providence: Brown University Press, 1967.

Landauer, T. K., \& Streeter, L. A. Structural differences between common and rare words: Failure of equivalence assumptions for theories of word recognition. Journal of Verbal Learning and Verbal Behavior, 1973, 12, 119-131.

Mayzner, M. S., \& Tresselt, M. E. Tables of single-letter and digram frequency counts for various word tength and letter-position combinations. Poychonomic Monograpb Supplem en ts, 1965, 1, 13-32.

Miller, G. A., Bruner, J. S., \& Postman, L. Familiarity of letter sequences and tachistoscopic identification. Journal of General Psychology, 1954, 50, 129-139. 
Millward, R. B., Aikin, J. O., \& Wickens, T. D. The Human Learning Laboratory at Brown University. In Computer in the prychological laboratory, Vol. 2. Maynard, Mass.: Digttal Equipment Corporation, 1972.

Neisser, U. Cognitive poychology. New York: Appleton-Century-Crofts, 1967.

Owsowitz, S. E. The effects of word familiarity and letter structure familiarity on the perception of Words. Rand Corporation Publications, No. P-2820, 1963.

Reicher, G. M. Perceptual recosnition as a function of meaningfulness of stimulus material. Joumal of Experimental Psychology, 1969, 81, 274-280.

Rubenstein, H., Garfield, L., \& Millikan, J. Homographic entries in the internal lexicon. Joumal of Verbal Learning and Verbal Behavior, 1970, 9, 487-492.

Rubenstein, H., Lewis, S. S., \& Rubenstein, M. A. Homographic entries in the internal lexicon: Effects of systematicity and relative frequency of meanings. Journal of Verbal Learning and Verbal Behavior, $1971,10,5762$.

Rumelhart, D. E., \& Siple, P. The process of recognizing tachistoscopically presented words. Psychological Review, $1974,81,99-118$.
Smith, E. E.. \& Spoehr, K. T. The perception of printed English: A theoretical perspective. In B. H. Kantowitz (Ed.), Human information processing: Tutorials in performance and cognition. Potomac, Md.: Erlbaum Press, 1974.

Smith, F. Understanding neading. New York: Holt, Rinehart Winstion, 1971.

Solomon, R. L., \& Howes, D. H. Word-probability, personal values, and visual duration thresholds. Psycholodeal Review, $1951,58,256-370$.

Trabasso, T., Rollins, H. \& Shaughnessy, E. Storage and verification stages in processing concepts. Cognitive Psy chology, 1971, 2, 239-289.

Wheeler, D. D. Processes in word recognition. Cognitive Psy chology, 1970, 1, 59-85.

Winer, B. J. Statistical principles in experimental desien. New York: McGraw-Hill, 1962,

(Received for publication December 26, 1974; revision received February 7,1975 .) 